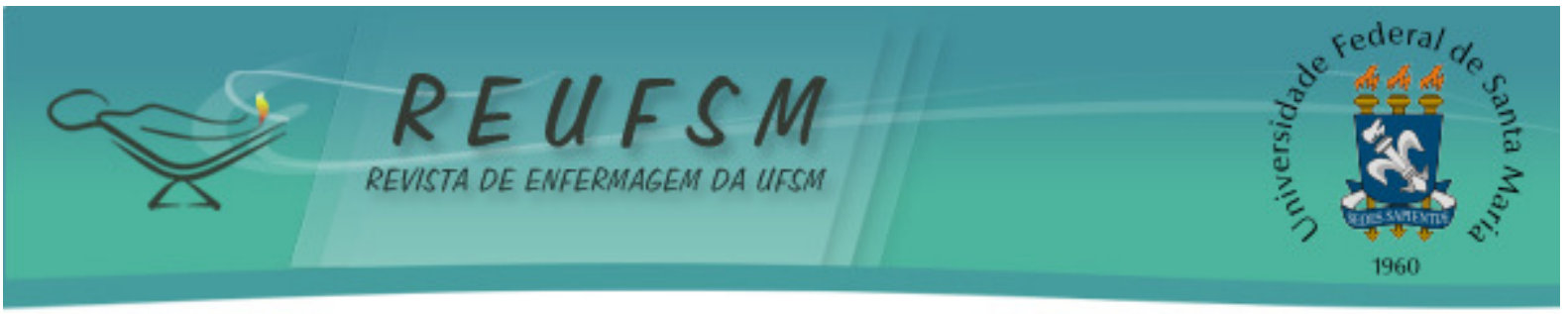

ARTIGO ORIGINAL

\title{
A CONSULTA DE ENFERMAGEM NA ESTRATÉGIA DE SAÚDE DA FAMÍLIA: REALIDADE DE UM DISTRITO SANITÁRIO
}

\author{
THE NURSING CONSULTATION ON FAMILY HEALTH STRATEGY: THE REALITY OF A \\ HEALTH DISTRICT
}

\section{CONSULTA DE ENFERMERÍA EN LA ESTRATEGIA DE SALUD DE LA FAMILIA: LA REALIDAD DE UN DISTRITO SANITARIO}

\author{
Kelly Maciel Silva ${ }^{1}$ \\ Silvia Maria Azevedo dos Santos ${ }^{2}$
}

\section{Doi: $10.5902 / 2179769218079$}

RESUMO: Objetivo: discutir as fragilidades e os aspectos limitantes para a execução da consulta de enfermagem no contexto da Estratégia de Saúde da Família. Método: pesquisa qualitativa, convergente-assistencial, cujos dados foram coletados entre maio e junho de 2012, por meio de entrevista estruturada com 20 enfermeiros, que atuam na Estratégia de Saúde da Família de um Distrito Sanitário do Sul do país. A análise dos dados envolveu processos de apreensão, síntese, teorização e transferência, resultando três categorias: percepção do enfermeiro acerca da consulta de enfermagem; a dialética da consulta de enfermagem entre os membros da equipe e os usuários; o cotidiano do trabalho. Resultados: a consulta de enfermagem é uma importante ferramenta de educação em saúde, favorece o vínculo profissional e usuário, possibilita o desenvolvimento da autonomia e independência profissional. Considerações finais: apesar do reconhecimento do papel da consulta de enfermagem na práxis dos enfermeiros ainda se verifica entraves para sua execução.

Descritores: Enfermagem; Prática profissional; Atenção primária de saúde; Processos de enfermagem.

ABSTRACT: Aim: to discuss the flaws and limitating aspects for the accomplishment of the nursing consutation practice in the context of Family Health Strategy. Method: it is a qualitative study, converging-assistential, in which the data were collected from May to June/2012 through structured interviews with 20 nurses who work in the Family Health Strategy of a Sanitary District of the South. The data analysis involved processes of apprehension, synthesis, theorization and transference, resulting in three categories: perception of nurses about nursing consultation; the dialectic of nursing consultation between team members and users; the daily work. Results: showed that the nursing consultation is an important health education tool, which enhances a link between the professional and the user, enables the development of autonomy and professional independence. Final Considerations: Although the role of the nursing consultation praxis of nurses is significantly recognized, there is still a number of barriers to their implementation.

Descriptors: Nursing; Professional practice; Primary health care; Nursing process.

\footnotetext{
${ }^{1}$ Enfermeira, Mestre em Enfermagem. Universidade Federal de Santa Catarina. Florianópolis, Santa Catarina, Brasil. E-mail: Kellymacielsilva@yahoo.com.br

2 Enfermeira, Doutora em Educação. Universidade Federal de Santa Catarina. Florianópolis, Santa Catarina, Brasil. E-mail: sazevedoms@gmail.com
} 


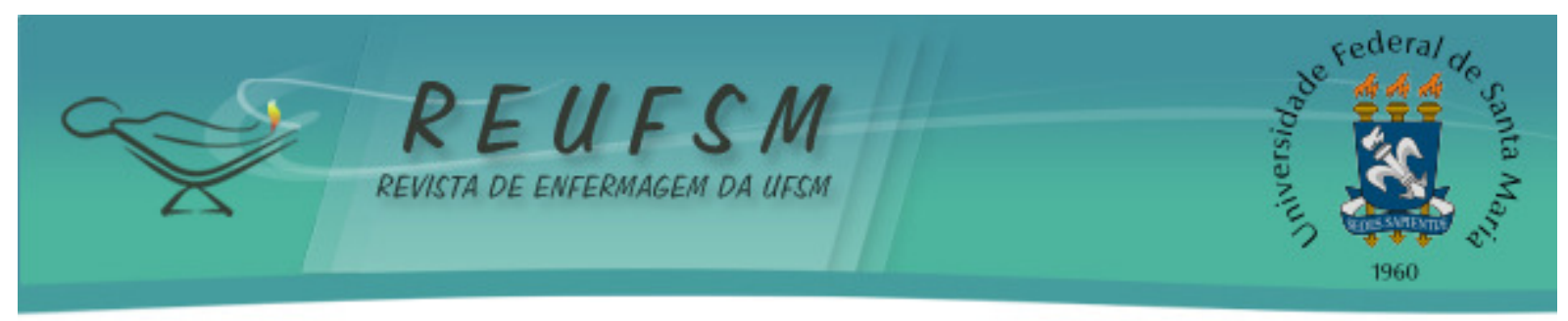

RESUMEN: Objetivo: discutir la práctica de la consulta de enfermería en la Estrategia Salud de la Família. Método: investigación cualitativa, convergente-asistencial, con datos recolectados entre Mayo y Junio/2012 en entrevistas estructuradas con 20 enfermeros que actúan en la Estratégia de Salud dela Família. El análisis involucró procesos de aprehensión, síntesis, teorización y transferencia, lo que resulta en tres categorías: la percepción de las enfermeras sobre la consulta de enfermería; la dialéctica de la consulta de enfermería entre los miembros del equipo y los usuarios; el trabajo cotidiano. Resultados: la consulta de enfermería es una herramienta importante de educación de la salud, que promueve la relación entre profesionales y usuarios y el desarrollo de la autonomía e independencia profesional. Consideraciones finales: aunque haya el reconocimiento del papel de la consulta de enfermería en la praxis de los enfermeros, hay barreras para su implementación.

Descriptores: Enfermería; Práctica profesional; Atención primaria de salud; Procesos de enfermería.

\section{INTRODUÇÃO}

A Consulta de Enfermagem (CE) é uma atividade específica do enfermeiro, podendo ser considerada uma ferramenta de educação em saúde utilizada prioritariamente para promoção da saúde e melhoria da qualidade de vida dos indivíduos. Foi definida pelo Comitê de Consulta de Enfermagem como sendo a "atividade diretamente prestada pela enfermeira ao cliente, onde são identificados problemas de saúde-doença, prescritas e implementadas medidas que contribuam com a promoção, proteção, recuperação ou reabilitação do cliente". 1:407

A realização da CE tem seu arcabouço legal sustentado pela Lei do Exercício Profissional, $\mathrm{N}^{\circ} 7.498 / 86$, que a legitima como sendo uma atividade privativa do enfermeiro, ou seja, está entre as atividades que somente podem ser executadas pelo enfermeiro. ${ }^{2} \mathrm{O}$ termo CE utilizado usualmente em ambientes ambulatoriais, refere-se ao Processo de Enfermagem, o qual deve ser realizado em todos os ambientes, públicos ou privados, em que ocorre o cuidado profissional de enfermagem. ${ }^{3}$

A realização da CE envolve tomada de decisão baseada em conhecimentos científicos e procedimentos que são sistematizados e avaliados constantemente, tornandose um importante instrumento para o desenvolvimento do pensamento clínico necessário para o cuidado de enfermagem. ${ }^{4}$ Entretanto, a criatividade e a flexibilidade no desenvolvimento da CE são diferenciais que tornam possíveis a utilização de outros mecanismos de intervenção como a escuta, o acolhimento e o vínculo. ${ }^{5}$

A Estratégia de Saúde da Família (ESF) é considerada o eixo estruturante da reorganização do modelo de atenção à saúde no Sistema Único de Saúde (SUS), e tem como objetivo a realização de ações de promoção e proteção à saúde de indivíduos, famílias e comunidades por meio do trabalho de equipes multiprofissionais. Deve ter em sua configuração mínima os seguintes profissionais: médico, enfermeiro, auxiliar ou técnico de enfermagem e agentes comunitários de saúde, tendo sob sua responsabilidade 0 acompanhamento de no máximo quatro mil habitantes, sendo a média recomendada de três mil habitantes. ${ }^{6}$

Ao remeter ao trabalho do enfermeiro na ESF sabe-se que a CE está entre as atribuições mínimas específicas desse profissional, e essa prática associada à adoção de protocolos de saúde possibilita que seu trabalho seja desenvolvido de forma mais autônoma e resolutiva. Entretanto, percebe-se que muitos enfermeiros da ESF não se apropriam dessa prática. Desta forma, torna-se essencial que a realização da CE esteja inserida de forma mais efetiva na práxis do enfermeiro da ESF. 


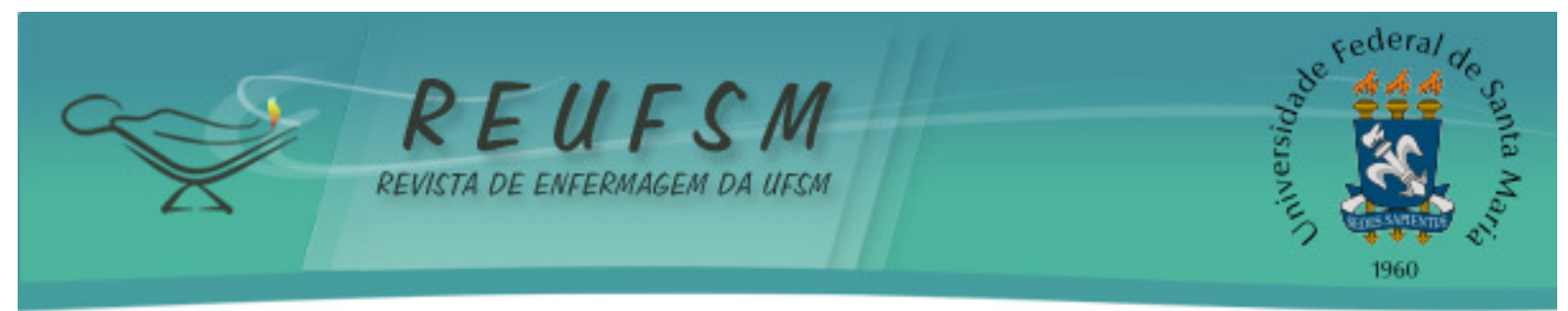

Porém, para o efetivo exercício da CE faz-se necessário mudanças na prática assistencial, bem como o enfermeiro necessita de um conjunto de conhecimentos (saber), habilidades (saber fazer) e atitudes (saber ser) que evidenciam sua competência profissional. $^{4}$

Por isso, o presente artigo tem como objetivo discutir as fragilidades e os aspectos limitantes para a execução da CE no contexto da ESF, bem como os aspectos que podem potencializar essa prática.

\section{MÉTODO}

Trata-se de uma pesquisa com abordagem qualitativa, do tipo exploratório descritivo em que se adotou como referencial metodológico a Pesquisa ConvergenteAssistencial (PCA). A escolha desse tipo de pesquisa foi pelo fato de estar orientada para a resolução ou minimização de problemas que na prática o enfermeiro enfrenta, nas possibilidades de mudanças e de introdução de inovações nas práticas de saúde. ${ }^{7}$

O estudo foi desenvolvido no Município de Florianópolis/SC, junto aos enfermeiros de um Distrito Sanitário da Secretaria Municipal de Saúde. Florianópolis conta com 50 Centros de Saúde (CS) divididos em cinco Distritos Sanitários (DS): Norte, Centro, Sul, Leste e Continente. A coleta de dados ocorreu no Distrito Sanitário do Continente, por ser o cenário de prática assistencial da pesquisadora principal. $\mathrm{Na}$ pesquisa convergenteassistencial o espaço físico para a pesquisa é aquele onde foram identificados o problema a ser solucionado ou mudanças a serem feitas. ${ }^{7}$

Participaram deste estudo 20 enfermeiros que compõem equipes da ESF em 11 CS, perfazendo o total de enfermeiros que estavam atuando na assistência durante o período de coleta de dados. Para seleção dos participantes utilizaram-se os seguintes critérios: ser enfermeiro do Distrito Sanitário Continente; compor equipe da ESF; e estar desenvolvendo atividades assistenciais no município há no mínimo seis meses. A coleta dos dados ocorreu no período de maio e junho de 2012.

As entrevistas foram realizadas no local de trabalho dos participantes mediante consentimento prévio, foram audiogravadas, e posteriormente transcritas, com duração média de 30 minutos. No momento da entrevista solicitou-se aos informantes que realizassem a leitura e assinatura do Termo de Consentimento Livre e Esclarecido (TCLE), em duas vias, sendo uma cópia para arquivo da pesquisadora e outra para o participante. Garantiu-se o anonimato dos participantes. Os participantes foram identificados com a letra E, da palavra "enfermeiro", seguida de número arábico sequencial. A pesquisa foi submetida ao Comitê de Ética da Universidade Federal de Santa Catarina e aprovada conforme o Parecer Consubstanciado № 21532.

A análise dos dados foi realizada segundo os preceitos da Pesquisa ConvergenteAssistencial, ${ }^{7}$ a qual é composta pelos seguintes passos:

Processo de apreensão: iniciou-se com a coleta dos dados, em que as informações resultantes dos encontros foram lidas sucessivas vezes para aproximação dos conteúdos das falas. A seguir, os dados foram concentrados em grupos determinados pelos temas mais frequentes, iniciando o processo de codificação dos relatos. Processo de síntese: nessa etapa as informações encontradas na fase de apreensão foram analisadas subjetivamente, buscando associações e variações dessas informações a fim de codificá-las. Os códigos foram reagrupados por semelhança e este processo resultou em cerca de 20 diferentes agrupamentos, que após minuciosa leitura e análise originaram as categorias. Processo de teorização: esta fase ocorreu à medida que se buscou interpretar os achados à luz da literatura e do referencial teórico que sustenta este estudo. Processo de transferência: é a 


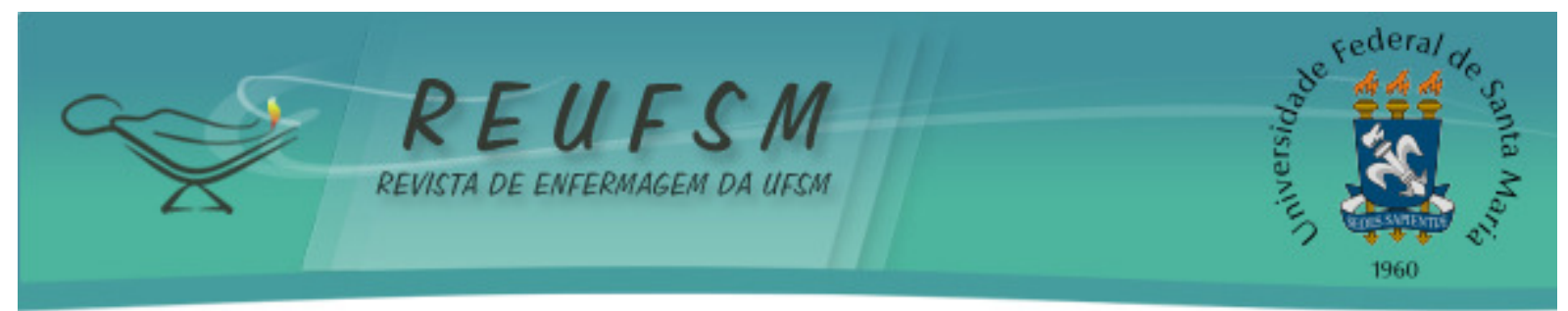

etapa final do processo analítico, consiste em dar significado a achados e descobertas procurando contextualizá-los em situações similares, visando à socialização dos resultados.

Para dar real sentido às descobertas teve-se a intenção de responder às perguntas de pesquisa, no que se refere a quais as dificuldades encontradas no cotidiano do trabalho da ESF para a realização da CE e como os enfermeiros de um Distrito Sanitário podem contribuir para mudança dessa realidade. De acordo com os princípios da PCA, se proporcionou aos enfermeiros a oportunidade para refletir acerca da realização da CE, buscando soluções para problemas enfrentados na prática.

0 processo reflexivo dos enfermeiros acerca das necessidades de fortalecimento da CE na ESF é uma intencionalidade da PCA, uma vez que as mudanças no contexto da prática só ocorrerão se houver envolvimento dos responsáveis pelas práticas, sendo a inclusão deles em todo o processo de pesquisa uma maneira para que isso ocorra.

\section{RESULTADOS E DISCUSSÃO}

\section{A prática da consulta de enfermagem na percepção dos enfermeiros}

Ao exteriorizar sua percepção acerca da CE, observa-se que os informantes consideraram ter um diferencial em sua formação, que thes conferia competência para desenvolver ações de educação em saúde, onde a CE é um espaço propício para essa atividade, conforme evidenciado na fala a seguir:

a CE é um momento em que o enfermeiro pode aproveitar o papel de educador, orientar sobre diversas questões de prevenção, promoção da saúde, adesão ao tratamento [...] damos orientações que nenhum outro profissional vai dar. (E17)

Historicamente o enfermeiro desempenha um papel importante nas atividades de educação em saúde. De acordo com um estudo qualitativo realizado com enfermeiros de equipes da saúde da família do município de Montes Claros/Minas Gerais, com objetivo de demonstrar os significados e intenções da prática educativa em saúde, as ações desenvolvidas podem ser divididas em duas categorias, descritas como dialógicas e hegemônicas. Na primeira, encontram-se as práticas pedagógicas que estimulam a participação dos sujeitos, bem como considera o conhecimento prévio das pessoas no processo educativo. Já no campo oposto, das condutas hegemônicas, encontra-se uma educação autoritária, prescritiva e restrita a mudanças de comportamento e fortemente ancorada nos aspectos biológicos do processo saúde e doença. ${ }^{8}$

Nesse sentido, a prática educativa que se aproxima do dialogismo representa um dos principais elementos para a promoção da saúde. Configura-se a partir da participação da população, de suas necessidades, de seu estilo de vida, crenças e valores, desejo, opções, experiências, da subjetividade e intersubjetividade, no contexto cultural-sóciopolítico em que vive. ${ }^{9}$ Nesse sentido, a ESF tem um espaço que possibilita tais ações, em que se percebe que o trabalho do enfermeiro está se voltando para os aspectos educativos do cuidado.

Além desse espaço para educação em saúde, os enfermeiros pesquisados sinalizaram que a CE potencializa a vinculação com os usuários, favorecendo o acesso deles ao sistema de saúde, conforme se constata nas falas a seguir: 


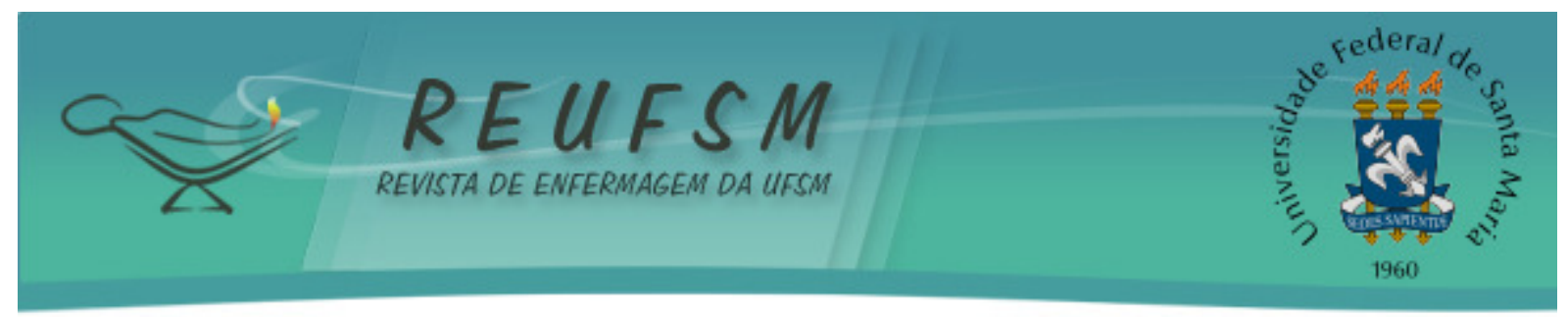

a CE possibilita a criação de vínculo com o paciente. (E5)

na CE as pessoas têm mais tempo para tirar dúvidas, estamos mais disponíveis para a escuta. (E19)

O vínculo pode ser caracterizado como uma relação de cumplicidade entre usuários e profissionais, sendo a base para a construção de confiança entre os envolvidos. 0 reconhecimento mútuo entre serviço e comunidade, respeito e empatia são indispensáveis na construção do vínculo. ${ }^{10}$

A disponibilidade para a escuta presente no atendimento dos enfermeiros pesquisados demonstra respeito e compromisso com a comunidade. Esse fato, somado à maior resolutividade dos problemas da população, a partir da CE, favorece a confiança da população no enfermeiro, que se torna, muitas vezes, o profissional de referência para o usuário no CS.

Nessa ótica, a CE pode ser considerada uma importante estratégia de cuidado na ESF e também um elemento indispensável para a criação de vínculo, uma vez que estreita as relações entre o enfermeiro e o sujeito atendido. Essa aproximação pode favorecer o desenvolvimento das ações propostas na CE, bem como garantir laços de confiança e corresponsabilidade entre os envolvidos, subsidiando condições para melhora da qualidade de vida dos usuários.

Conforme se conclui das falas a seguir, ao realizar a CE o enfermeiro sente-se realizando uma atividade importante, de valoração profissional, em que pode desenvolver sua independência e autonomia.

Realizando a CE me sinto assumindo meu papel de enfermeira [...], fazendo o que nos compete, que é esse atendimento mais diferenciado. (E7)

Temos um espaço muito bom na ESF para exercer a autonomia profissional, principalmente na CE. (E13)

Nessa perspectiva, a CE é entendida como uma oportunidade para práticas profissionais autônomas, que demanda habilidades e capacidades cognitivas, psicomotoras e afetivas, bem como flexibilidade, criação e inovação de planos de cuidados que sejam adequados às necessidades dos usuários. ${ }^{11}$ Dessa forma, quanto melhor implementada a autonomia profissional e o processo de trabalho da enfermagem, mais oportunidades 0 enfermeiro terá em atuar com base no conhecimento técnico e científico. ${ }^{12}$

\section{A dialética da consulta de enfermagem entre os membros da equipe da estratégia de saúde da família e os usuários}

A CE de enfermagem foi bem-vista pela maioria dos membros da equipe da ESF, demostrando a necessidade de atendimento multiprofissional e em equipe para atender as necessidades dos usuários, como se evidencia no relato que segue:

tem muitos médicos e outros profissionais que trabalham junto com o enfermeiro, encaminhando para nós, dando importância para o que é feito na CE. (E2) 


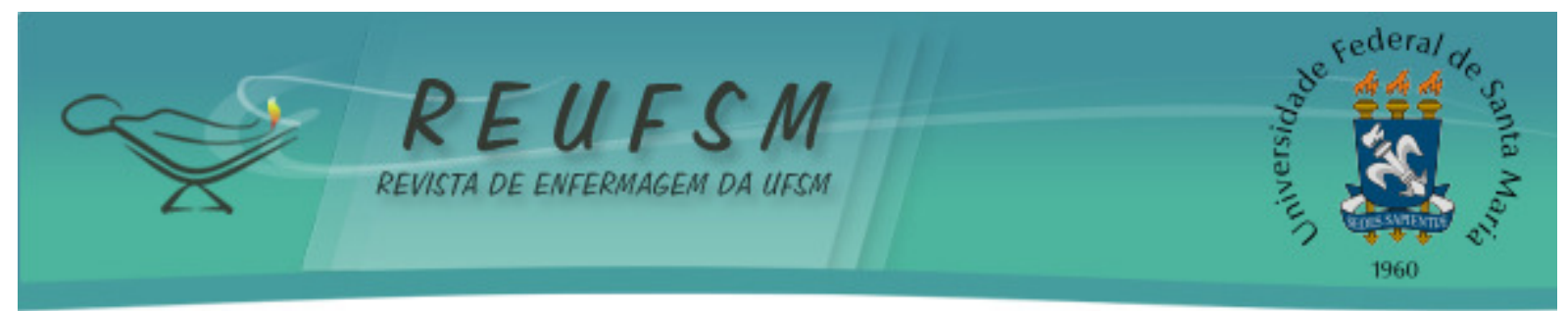

Essa forma de trabalho vai ao encontro das propostas da ESF, que propõe, entre as características do processo de trabalho das equipes, a prática do trabalho interdisciplinar, integrando áreas técnicas e profissionais de diferentes formações. ${ }^{6}$ Em contraponto a essa aceitação, destacaram a resistência de alguns membros da equipe de enfermagem no que se refere à dedicação do enfermeiro à CE.

Alguns técnicos acham que fazendo a CE nós estamos fugindo do serviço, do serviço deles, é claro. Eles não fazem o nosso, mas acham que a gente deve ajudar a fazer o deles. (E7)

Nessa fala fica evidente o conflito no processo de trabalho entre a equipe de enfermagem, em que alguns técnicos de enfermagem não aceitavam a diferenciação de atribuições entre sua prática e a dos enfermeiros. Muitos desses conflitos são heranças da divisão interna do trabalho da enfermagem, que deu origem a várias modalidades, uma vez que a enfermagem, no Brasil, atualmente é exercida por três categorias profissionais, o enfermeiro com nível superior, o técnico e auxiliar com nível médio. ${ }^{2}$

Essa subdivisão na enfermagem reproduz a fragmentação taylorista, onde a coordenação do trabalho, dentro do grupo, é feita pelo profissional de nível superior, que delega atividades aos trabalhadores de nível médio. A hierarquia de trabalho e saberes fica evidente nas relações, resultando em conflitos, explícitos ou não, entre os diversos agentes. ${ }^{13}$

Nesse sentido, o processo de trabalho na ESF parece reproduzir os modelos gerenciais que deveriam superar. Sobrepujar a tradição em gerenciar o trabalho em saúde a partir de regras tayloristas torna-se um dos dilemas contemporâneos da ESF. ${ }^{14}$ Para resolver esses conflitos o enfermeiro, como gerente da assistência de enfermagem, necessita ser capaz de identificar, analisar e conduzir as situações conflituosas no trabalho, por meio do diálogo e da interação com os componentes da equipe de enfermagem visando o atendimento das necessidades dos usuários. ${ }^{15}$

$\mathrm{Na}$ relação com os usuários, os enfermeiros referiram uma boa aceitação da CE por parte da maioria, destacaram que percebem a diminuição da resistência deles à medida que conhecem o trabalho do enfermeiro, como se evidencia na fala a seguir:

a resistência era mais inicial, pois os usuários estavam centrados no médico, depois que conhecem nosso trabalho aceitam bem. (E4)

Essa fala revela que o enfermeiro, ao desenvolver a CE, assume atribuições e características que torna conhecida e legitimada a sua prática profissional, e a aceitabilidade de sua atuação pela população vem se mostrando de maneira ampliada na ESF. Por outro lado, ainda aparece no discurso de alguns enfermeiros a percepção de incompreensão por parte dos usuários da importância da CE, como se constata nas falas que se seguem:

ainda tem resistência [...] acham que consulta é só com médico, com a enfermeira é só uma conversa. (E2)

muitos pacientes vêm para a CE e não sabem direito o que vai ser feito [...] parece que não dão muita importância. (E3)

No imaginário popular, muitas vezes, o termo "consulta", na área da saúde, refere-se à consulta médica. Isso pode justificar a resistência inicial de alguns usuários, 


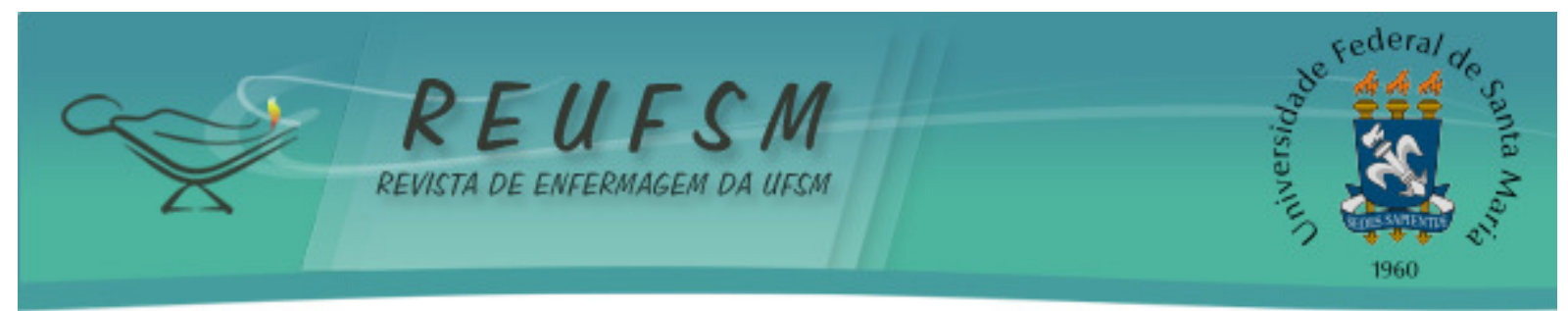

porém, conforme relatos dos enfermeiros, a CE vem ganhando espaço e reconhecimento na ESF. Esse movimento contribui para a substituição do modelo médico centrado, conforme proposto pela ESF.

\section{Cotidiano do trabalho e a prática da consulta de enfermagem}

$\mathrm{Na}$ ESF o enfermeiro tem um campo amplo de atuação, onde encontra espaço para desempenhar suas competências assistenciais, educativas e gerenciais. No cotidiano do trabalho na ESF, os enfermeiros pesquisados descreveram a realização de consultas programadas, atendimento da demanda espontânea, atividades coletivas, visitas domiciliares, reuniões de equipe, supervisão do trabalho dos ACS e da equipe de enfermagem e atividades administrativas.

$\mathrm{Na}$ realização de suas atividades privativas, como a consulta de enfermagem, os participantes deste estudo referiram que organizavam o atendimento a partir de agenda programada por grupo de atenção. Dessa forma, a assistência de enfermagem à saúde da mulher está sendo priorizada, como pode ser observado nas emissões abaixo:

teve uma época que conseguia atender até os hipertensos $e$ diabéticos, mas agora priorizamos as gestantes, puérperas $e$ preventivo [exame citopatológico do colo do útero]. (E19)

nós enfermeiras só temos um consultório para atender, então priorizamos a saúde da mulher. (E10)

Como uma das justificativas a essa prioridade, está o fato dos atendimentos serem organizados de acordo com a disponibilidade de consultórios, em que frequentemente falta consultório para o enfermeiro realizar consulta de enfermagem a todos os grupos de atenção. $\mathrm{O}$ que foi explicitado pelos informantes, como exposto a seguir:

temos problemas de espaço, pois são três enfermeiras e um único consultório. (E6)

tenho apenas quatro períodos na semana de consultório, não dá para atender todo mundo. (E17)

Apesar da Política Nacional de Atenção Básica orientar como infraestrutura necessária à realização de ações na Atenção Básica a presença de consultório de enfermagem, na prática percebe-se um aumento do número de equipes sem a adequada estrutura física dos CS. ${ }^{6}$ Essa realidade pode comprometer o trabalho assistencial do enfermeiro na ESF e contribuir para a baixa produção de consultas de enfermagem. Fato preocupante para a profissão, uma vez que a diminuição dessas consultas pode significar um recuo da clínica no trabalho do enfermeiro. ${ }^{16}$

Como as metas relacionadas à saúde da mulher são, muitas vezes, mais cobradas pelo gestor municipal, esse atendimento acaba destacando-se, mesmo que esse grupo populacional não seja o que mais demande atenção no território. As metas deveriam ser pactuadas em nível local considerando a realidade do território, a capacidade instalada e necessidades de enfrentamento. Porém, o que se verifica na realidade é que as equipes não possuem espaços de escuta e discussão, sendo consideradas, muitas vezes, meras executoras das ações. ${ }^{17}$ 


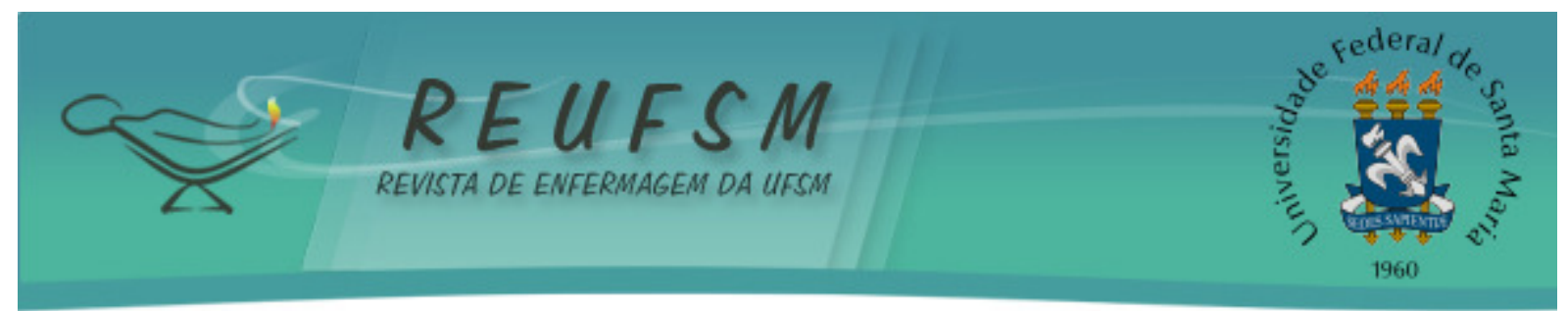

Outro aspecto destacado pelos informantes deste estudo foi a quantidade de atividades administrativas desenvolvidas pelos enfermeiros, que aparece como um empecilho para realização de atividades assistenciais e privativas, como a consulta de enfermagem, conforme se evidencia nas seguintes falas:

temos que preencher muitos relatórios. (E14)

se ficamos muito na assistência os relatórios ficam todos atrasados, esses relatórios tem data para entregar. (E7)

temos diversas reuniões, fica complicado abrir uma agenda para CE. (E10)

A gerência é uma prática inerente ao processo de trabalho na ESF, porém a divisão dessa tarefa normalmente não ocorre de maneira equiparada entre os membros da equipe. $\mathrm{Na}$ prática, observa-se que comumente o enfermeiro torna-se responsável por essa função.

Partindo-se do pressuposto de que o cuidado deve ser o foco principal do processo de trabalho do enfermeiro e de que as ações gerenciais realizadas deveriam visar à melhoria da qualidade do cuidado prestado, percebe-se no discurso dos enfermeiros um distanciamento entre o administrar e o cuidar. Os enfermeiros parecem ter direcionado a dimensão gerencial do seu processo de trabalho para o preenchimento de relatórios e não conseguem identificar seu papel como gerente do cuidado.

0 que irá diferenciar o gerenciamento feito pelos enfermeiros como sendo o efetivo gerenciamento do cuidado será o seu posicionamento perante o modo que desenvolvem o trabalho. Uma vez que, as ações de cuidado direto e indireto devem ocorrer de forma articulada e integrada, não havendo separação entre a dimensão assistencial e gerencial da assistência. ${ }^{18}$

Outro ponto que fomenta a discussão acerca da forma de agir do enfermeiro em "fazer de tudo um pouco" é a frequente falta de outros profissionais e a postura do enfermeiro em assumir a função destes. Isso gera uma instabilidade que prejudica a atuação profissional do enfermeiro na ESF, uma vez que diminui o tempo que teria para realizar atividades especificas da profissão. Os depoimentos a seguir demonstram que apesar de não concordarem com a situação, os enfermeiros assumiam posição passiva ao lidar com essas contradições:

[...] sempre tem que cobrir algum setor por falta de profissionais. (E6)

falta um técnico, o enfermeiro tem que assumir a função, falta alguém na farmácia, temos que ir, falta o coordenador, é o enfermeiro que chamam para tudo [...]. (E18)

acaba faltando tempo para fazer a CE. (E11)

Essas falas revelam a conduta flexível dos enfermeiros, que, de forma geral, aceitam assumir atividades de competência de outros profissionais em detrimento de sua prática privativa. Essas atitudes contribuem para o surgimento e manutenção de equívocos acerca do processo de trabalho do enfermeiro. 0 enfermeiro deve ater-se em exercer a enfermagem de acordo com a Lei do Exercício Profissional, ${ }^{2}$ ou seja, realizar, com autonomia, as atividades para as quais possui competência técnica e legal, e não destinar 


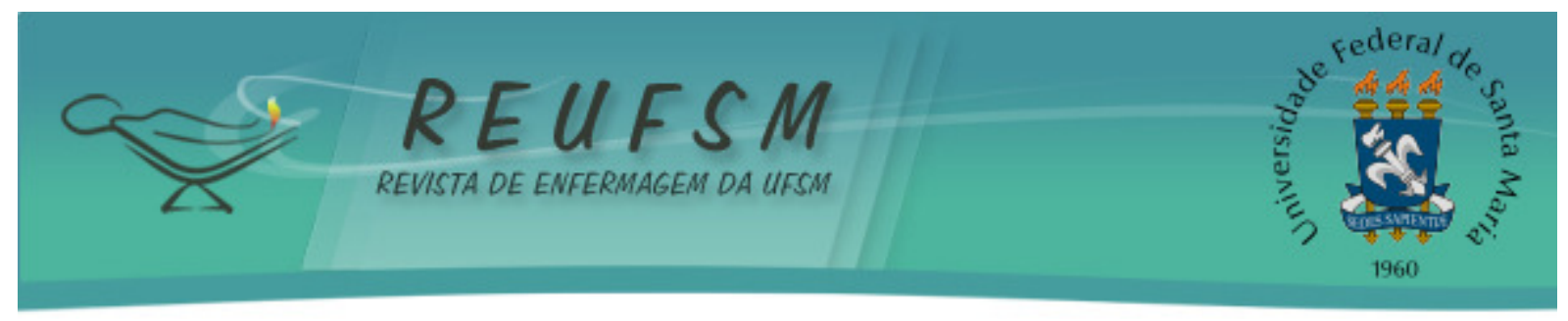

seu tempo de trabalho realizando funções que competem a outro profissional. Uma vez que, na ESF o enfermeiro tem um campo de atuação importante, que possibilita maior autonomia profissional, bem como maior visibilidade ao seu trabalho. ${ }^{19}$

0 enfermeiro, por ser o responsável pelas atividades de enfermagem desenvolvidas no CS, fica em situação de sobrecarga quando ocorre o absenteísmo de membros da equipe de enfermagem, em que muitas vezes tem que deixar de fazer suas atividades privativas para dedicar-se às atividades de competência dos técnicos de enfermagem. No cotidiano dos enfermeiros pesquisados isso era uma constante.

Pensando na equipe de enfermagem, uma alternativa para minimizar esse problema é monitorar os índices de ausência dos profissionais. Diante de faltas, garantir um quantitativo de pessoal adicional para cobertura dessas ausências, evitando a sobrecarga de trabalho dos outros profissionais, bem como garantir a segurança e qualidade da assistência prestada. ${ }^{20}$

Percebe-se que o desvio de função, a falta de espaço físico, o trabalho multifacetado do enfermeiro e a burocratização do cuidado são elementos deteriorantes da CE na ESF. Tais situações provocam reflexões sobre as condições inadequadas de trabalho enfrentadas pelos enfermeiros no cotidiano laboral.

Pesquisa realizada em um município do sul do Brasil, com objetivo de analisar a influência das condições de trabalho nas atividades dos enfermeiros da ESF, aponta o abismo existente entre as orientações prescritivas que constam nas políticas públicas de saúde e as condições concretas de trabalho disponibilizadas para sua realização. Onde a precarização do trabalho, para os enfermeiros, acarreta sobrecarga física e psíquica, além de desvio de função e redução da realização das atividades de acordo com os parâmetros profissionais como, por exemplo, o uso de metodologias de sistematização da assistência de enfermagem. ${ }^{21}$

Dessa forma, a sistematização da assistência de enfermagem é considerada um caminho para autonomia da profissão por ser uma metodologia de trabalho que contribui significativamente para a qualidade da assistência e do cuidado de enfermagem, bem como para visibilidade e reconhecimento do enfermeiro. ${ }^{22}$

\section{CONSIDERAÇÕES FINAIS}

Nessa pesquisa foi possível conhecer como se dá a prática da CE na percepção dos enfermeiros, que se configurou como uma ferramenta de cuidado que favorece o desenvolvimento de ações de educação em saúde, sendo considerada um instrumento de fortalecimento de vínculo entre o profissional e o usuário, bem como um espaço para o desenvolvimento da autonomia e independência profissional.

Os resultados mostram que os enfermeiros encontram situações adversas no cotidiano do trabalho, destacando a falta de consultório e o excesso de atividades administrativas, que limitam a realização da CE na ESF. Esse fato, aliado à diversidade de atividades não específicas da enfermagem desenvolvidas pelo enfermeiro na ESF, compromete sua identidade e a atuação profissional.

Destaca-se como limitação desta pesquisa a investigação de outros possíveis fatores que podem interferir no desenvolvimento da CE, tais como os aspectos organizacionais para a realização da CE, o processo de formação e educação continuada nos serviços. Como contribuição deste estudo à Enfermagem, espera-se sensibilizar e mobilizar os enfermeiros para reivindicarem condições adequadas de trabalho e intensificar a realização da $\mathrm{CE}$, uma vez que essa prática pode fortalecer a identidade profissional, além de contribuir para as respostas às necessidades de saúde da população. 


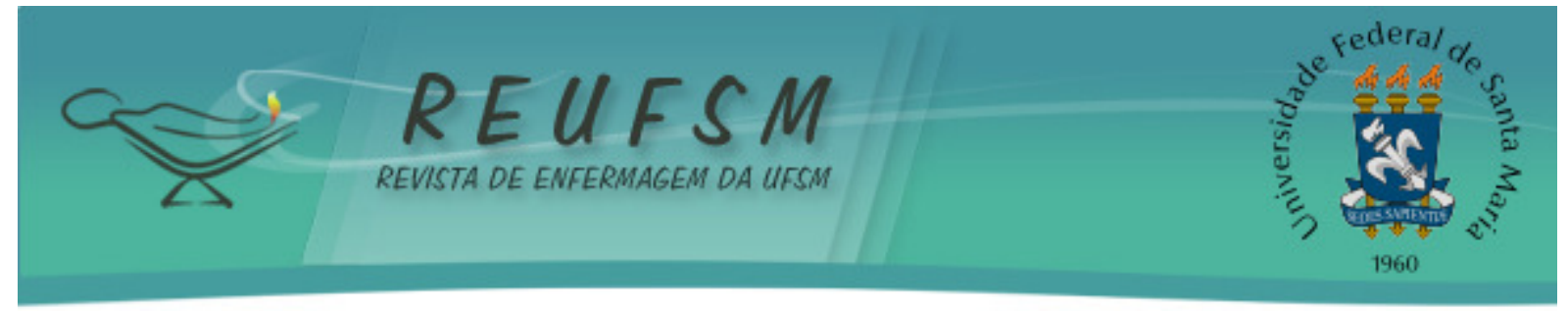

\section{REFERÊNCIAS}

1. Comitê de Consulta de Enfermagem. Rev Bras Enferm. 1979;32(4):407-8.

2. Conselho Federal de Enfermagem (COFEN). Lei $n^{\circ} 7.498$, de 25 de junho de 1986. Dispõe sobre a regulamentação do exercício da enfermagem e dá outras providências [Internet]. 1986 [acesso em 2012 ago 04]. Disponível em: http://www.cofen.gov.br/lei-n-749886-de25-de-junho-de-1986_4161.html.

3. Conselho Federal de Enfermagem (COFEN). Resolução n 358, de 15 de outubro de 2009. Dispõe sobre a Sistematização da Assistência de Enfermagem e a implementação do Processo de Enfermagem em ambientes, públicos ou privados, em que ocorre o cuidado profissional de Enfermagem, e dá outras providências. 2009 [acesso em 2016 mar 23]. Disponível em: http://www.cofen.gov.br/resoluo-cofen-3582009_4384.html.

4. Corradi EM. Aspectos gerenciais da Consulta de Enfermagem. In: Santos AS, Cubas MR, organizadores. Saúde Coletiva: linhas de cuidado e Consulta de Enfermagem. Rio de Janeiro: Elsevier; 2012. p. 45-60.

5. Macêdo SM, Sena MCS, Miranda KCL. Consulta de Enfermagem ao paciente com HIV: perspectivas e desafios sob a ótica de enfermeiros. Rev Bras Enferm. 2013;66(2):196-201.

6. Brasil. Ministério da Saúde. Portaria $n^{\circ} 2.488$, de 21 de outubro de 2011. Aprova a Política Nacional de Atenção Básica, estabelecendo a revisão de diretrizes e normas para a organização da Atenção Básica, para a Estratégia Saúde da Família (ESF) e o Programa de Agentes Comunitários de Saúde (PACS). Brasília: Ministério da Saúde; 2011 [acesso em 2012 jun 2012]. Disponível em: http://bvsms.saude.gov.br/bvs/saudelegis/gm/2011/prt2488_21_10_2011.html.

7. Trentini M, Paim L. Pesquisa convergente assistencial: um desenho que une o fazer e o pensar na prática assistencial em saúde-enfermagem. $2^{\mathrm{a}}$ ed. Florianópolis (SC): Insular; 2004.

8. Almeida ER, Moutinho CB, Leite MTC. Prática pedagógica de enfermeiros de saúde da família no desenvolvimento da educação em saúde. Interface (Botucatu) [Internet]. 2016;20(57):389-401. Disponível em: http://www.scielo.br/pdf/icse/2016nahead/18075762-icse-1807-576220150128.pdf.

9. Souza IVB, Marques DKA, Freitas FFQ, Silva PE, Lacerda ORM. Educação em Saúde e enfermagem: revisão integrativa da literatura. Rev Ciênc Saúde Nova Esperança. 2013;11(1):112-21.

10. Garuzi M, Achitti MCO, Sato CA, Rocha AS, Spagnuolo RS. Acolhimento na Estratégia Saúde da Família: revisão integrativa. Rev Panam Salud Publica. 2014;35(2):144-9.

11. Garcia TR. Sistematização da assistência de enfermagem: aspecto substantivo da prática profissional. Rev Esc Anna Nery. 2016;20(1):5-10.

12. Kraemer FZ, Duarte MLC, Kaiser DE. Autonomia e trabalho do enfermeiro. Rev Gaúcha Enferm. 2011;32(3):487-94.

13. Pires D. A enfermagem enquanto disciplina, profissão e trabalho. Rev Bras Enferm. 2009;62(5):739-44.

14. Ximenes Neto FRG, Sampaio JJC. Análise do processo de trabalho dos gerentes no território da Estratégia de Saúde da Família. Rev gerenc políticas salud. 2012;11(22):76-91. 


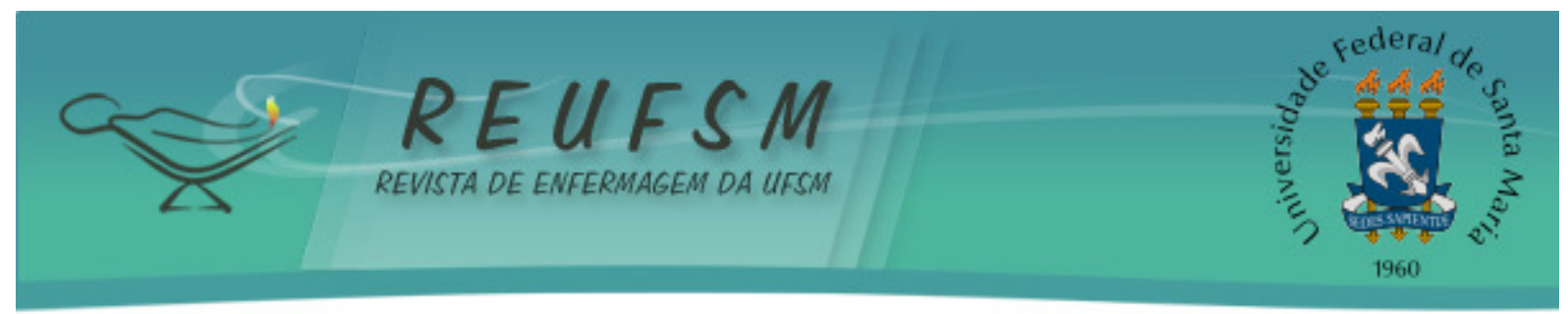

15. Santos JLG, Lima MADS, Pestana AL, Colomé ICS, Erdmann AL. Estratégias utilizadas pelos enfermeiros para promover o trabalho em equipe em um serviço de emergência. Rev Gaúcha Enferm. 2016;37(1):1-7.

16. Pires MRGM. Limites de possibilidades do trabalho do enfermeiro na estratégia saúde da família: em busca da autonomia. Rev Esc Enferm USP. 2011;45(N Esp 2):1710-5.

17. Cubas MR. Desafios para a enfermagem no alcance das metas da Atenção Primária. Rev Esc Enferm USP. 2011;45(2):1758-62.

18. Lanzoni GMM, Magalhães ALP, Costa VT, Erdmann AL, Andrade SR, Meirelles BHS. Tornando-se gerente de enfermagem na imbricada e complexa fronteira das dimensões assistencial e gerencial. Rev Eletrônica Enferm [Internet]. 2015;17(2):322-32. Disponível em: http://dx.doi.org/10.5216/ree.v17i2.29570.

19. Silva KM, Santos SMA. A práxis do enfermeiro da estratégia de saúde da família e o cuidado ao idoso. Texto \& Contexto Enferm. 2015;24(1):105-11.

20. Sancinetti RT, Soares AVN, Lima AFC, Santos NC, Melleiro MM, Fugulin FMT, et al. Taxa de absenteísmo da equipe de enfermagem como indicador de gestão de pessoas. Rev Esc Enferm USP. 2011;45(4):1007-12.

21. Bertoncini JH, Pires DEP, Scherer MDA. Condições de trabalho e renormalizações nas atividades das enfermeiras na saúde da família. Trab Educ Saúde. 2011;9 Supl 1:157-73.

22. Trindade LR, Silveira A, Ferreira AM, Ferreira GL. Compreensão do processo de enfermagem por enfermeiros de um hospital geral do sul do Brasil. Rev Enferm UFSM [Internet]. 2015;5(2):267-77. Disponível em: http://cascavel.ufsm.br/revistas/ojs2.2.2/index.php/reufsm/article/view/15923.

Data de recebimento: 19/05/2015

Data de aceite: $27 / 04 / 2016$

Contato do autor responsável: Kelly Maciel Silva

Endereço postal: Rua das Árvores, 128. São José/SC CEP: 88106/250

E-mail: kellymacielsilva@yahoo.com.br 